\title{
Decolorization and Degradation of Direct Blue 6 from textile wastewaters by Pseudomonas aeruginosa HS-DY012
}

\author{
Wu Jing ${ }^{1,2}$,Wu Cong ${ }^{1}$,Pei Nanmei ${ }^{1}$, Xu Huan ${ }^{1}$, Yu Yue ${ }^{1}$, Xu Biling ${ }^{1}$, \\ ZhengYongliang $^{1^{*}}$ \\ ${ }^{1}$ Hubei Key Laboratory of Economic Forest Germplasm Improvement and Resources \\ Comprehensive Utilization, Huanggang Normal University,146 Xingang II Road, Huangzhou, \\ 438000, China \\ ${ }^{2}$ College of Life Science and Technology, Huazhong Agricultural University, \\ No.1,Shizishan Street, Hongshan District,Wuhan , 430070,China \\ * Corresponding author, E-mail:zylgolden@126.com
}

\begin{abstract}
Keywords:Azo dyestuff; Direct Blue 6; Decolorization; Biodegradation; Pseudomonas aeruginosa Abstract. Wastewater discharged from printing and dyeing plants on both sides of the Yangtze River seriously threatens the ecological and water security. Direct Blue 6 is a synthetic chemical dye and widely used in textile and dyeing industry. In this study, Pseudomonas aeruginosa HSDY012 was used as a original strain in the decoloraziation of Direct Blue 6. Results indicated that HS-DY012 strain could completely decolorize and degrade $30 \mathrm{mg} / \mathrm{L}$ Direct Blue 6 dye in MSM medium within $18 \mathrm{~h}$ culturing at $35{ }^{\circ} \mathrm{C}$ on a shaker at $120 \mathrm{rpm}$. The optimum condition of decolorization and degradation were determined, i.e. temperature at $35^{\circ} \mathrm{C}$ and $\mathrm{pH} 7.0$, and the optimum concentration was $30 \mathrm{mg} / \mathrm{L}$. HS-DY012 strain could effectually decolor seleted two type dyes both Reactive Black 5 and Congo red with a high degradation rate, as well as Acid scarled GR and Vat Yellow 2 could be decolored partially.These results indicated that HS-DY012 strain was a great degrader with a broad-spectrum dye decolorization character and it has a potential application.
\end{abstract}

\section{Introduction}

Azo dyes are the majority of all textile dyestuffs and are the most commonly synthetic dyes in the textile, printing and dyeing industries, because of their low biodegradability, some of these dyes have been reported to accumulate in surface water and sediments[1]. As the largest type of dyes, azo dyes have differences structural based on one or more azo bonds $(-\mathrm{N}=\mathrm{N}-)$ bearing aromatic ring sand consequently give out a great variety of colors [2], and dominates the worldwide market of dyestuffs with a share of about $70 \%$ [3].Approximately $10-15 \%$ of the azo dyes are released into the environment during manufacturing and usage, and poses a potential health hazard to all forms of life in river and lake Basin, majority of these dyes is either toxic or mutagenic and carcinogenic and threaten the life in much aspects in environment[4].

Since they are highly recalcitrant to conventional wastewater treatment processes,azo dyes bearing effluents to the regulatory levelsusually cannot be efficiently decolorised and degraded. The release of azo dyes in effluent from relative painting and dyeing plants into the environment has become a major concern in wastewater treatment[5]. The recalcitrance of azo dyes has been attributed to the presence of azo bonds, which generally considered as xenobiotic.In addition, some azo dyes or their metabolites of decoloration and biodegradation may be carcinogens or mutagens[6]. Therefore, it is very important not only to environment protection but also to human health to decolorization and degradation completely of azo dyes remained in environment. Several anaerobic and aerobic microbial treatments have been suggested to enhance the decolorization and degradation of azo dyes[2,5].Up to date, biological degradation of some azo dyes such as Azo dye 4BS[8],Direct Black-38[1],Methyl Orange [9], and so on, have been reported. Other research suggested that the decolourisation mechanism occurs mainly by co-metabolism in the presence of a co-substrate used as carbon and energy source $[4,7,10]$.

In the present study, Direct Blue 6, a benzidine based azo dye with water soluble (Fig. 1), was selected as substance for carrying out microbial decolorisation and biodegradation studies. Microbe 
capable of mineralizing Direct Blue 6 was isolated and characteristics of decolorisation and biodegradation was advanced investigated.

\section{Materials and methods}

\section{Microorganism and culture medium}

The original strain HS-DY012 was isolated from a wastewater treatment pool of ShenGang Textile and Dyeing Plant in Huanggang city, Hubei province, and it was identified and belonged to Pseudomonas aeruginosa HS-DY012(data not show). Luria-Bertani medium(LB) and Mineral salt medium (MSM) was used in the tests and the composition of MSM was as follows $(\mathrm{g} / \mathrm{L}): \mathrm{KH}_{2} \mathrm{PO}_{4}$ $0.5, \mathrm{~K}_{2} \mathrm{HPO}_{4} 1.5, \mathrm{NaCl} 0.5, \mathrm{MgSO}_{4} .7 \mathrm{H} 2 \mathrm{O} 0.5$. All media were adjusted $\mathrm{pH}$ to 7.0 and autoclaved for $30 \mathrm{~min}$. HS-DY012 was incubated into Luria-Bertani liquid medium at $30^{\circ} \mathrm{C}$ for $15 \mathrm{~h}$, then the cells were harvested, centrifuged $\left(5000 \mathrm{r} / \mathrm{min}\right.$ for $10 \mathrm{~min}$ at $\left.4^{\circ} \mathrm{C}\right)$, washed for 3 times and suspended with sterile MSM medium as prepared inoculums.

\section{Decolouration and biodegradation assay}

Direct Blue 6 and other dyeswere supplied by Huanggang Shenggang Textile and Dyeing Company CO., LTD.Samples containing dyes were analyzed by Uv-vis spectrophotometer with Varian cary100 (USA). Bacterial growth was measured spectrophotometrically by optical density at $600 \mathrm{~nm}$ (OD600). The absorbance of Direct Blue 6 was measured spectrophotometrically at $571 \mathrm{~nm}$.

Dyes were added to the liquid MSM medium as an aqueous solution to a final concentration of 30 $\mathrm{mg} / \mathrm{L}$ for decolorization study. On the process of dye decolorization and degradation in MSMmedium, the samples were collected every $6 \mathrm{~h}$ interval.

\section{Results and discussion}

Dynamic decolorisation and biodegradation analysis

HS-DY012 strain was inoculated into MSM liquid medium containing $30 \mathrm{mg} / \mathrm{LDirect}$ Blue 6 dye and cultured at $35^{\circ} \mathrm{C}$ on a shaker at $120 \mathrm{rpm}$. Sample was taken every 6 hour and scanned with UVVis spectrophotometer. As showed from Figure 1, an absorption peak at $571 \mathrm{~nm}$ was observed at 0 $\mathrm{h}$, with theDirect Blue 6 dye degradation, the absorption peak was gradually decreased at $6 \mathrm{~h}$, and the peak was disappeared at $12 \mathrm{~h}$ and $18 \mathrm{~h}$. Meanwhile, the blue colour of solution was disappeared obviously with the degradation occurred. These results indicating the Direct Blue 6 dye wasdegraded completely by HS-DY012 strain and it is an effective degrader in Direct Blue 6 decolorization.

\section{Optimization of decolorization conditions}

The different decolorization and degradation condition of Direct Blue 6 by HS-DY012 strain were optimized with single factor and multi level experiment.As showed form figure 2A, HS-DY012 strain could effectively decolorize Direct Blue 6 at a wide range temperature from $25^{\circ} \mathrm{C}$ to $43^{\circ} \mathrm{C}$, and degradation rates of Direct Blue 6 inrange of these temperatures were exceed $50 \%$, indicating HS-DY012 strain could adapt to a wider temperature range and have potential application value in printing and dyeing wastewater treatment. Comprehensive consideration the decolorization and bacteria growth, the optimum temperature was $35^{\circ} \mathrm{C}$. 
A

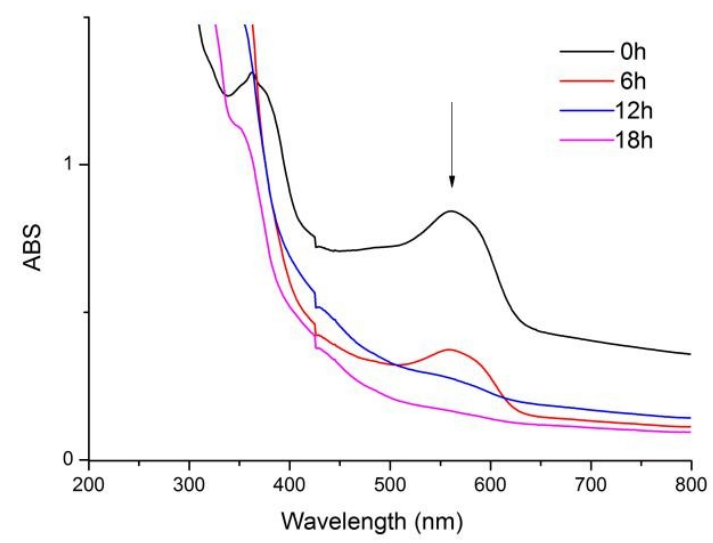

B

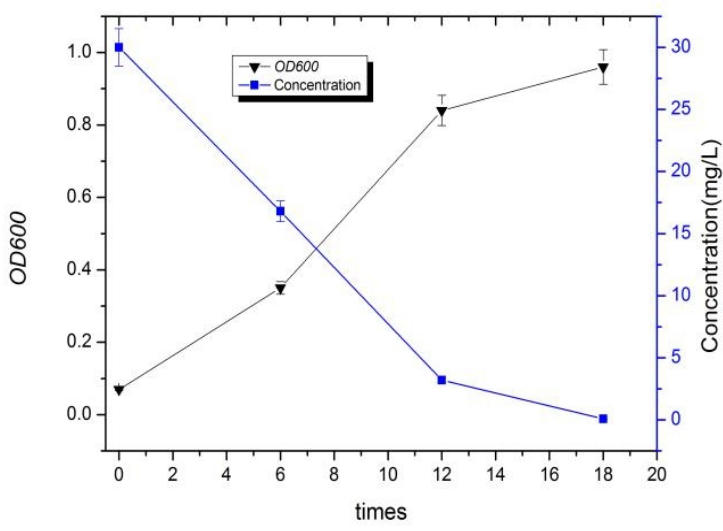

Figure 1.Degradation of Direct Blue 6 by HS-DY012 strain. (A) analysis results with UV-vis spectrophotometer, sample was scanned at $0 \mathrm{~h}, 6 \mathrm{~h}, 12 \mathrm{~h}, 18 \mathrm{~h}$ respectively in MSM medium containing $30 \mathrm{mg} / \mathrm{L}$ Direct Blue 6 dye; (B) Change of Direct Blue 6 dye concentration and bacteria growth $(\mathrm{OD} 600 \mathrm{~nm})$ at different time.

The $\mathrm{pH}$ value effected on not only the bacteria growth but also dyes solution. In our research, $\mathrm{pH}$ of aqueous solutionmedium was adjusted from 3.0 to 10.0 , which including $30 \mathrm{mg} / \mathrm{L}$ Direct Blue 6 and cultured at $35^{\circ} \mathrm{C}$ with $120 \mathrm{rpm}$ shaking for $24 \mathrm{~h}$. Results indicated that HS-DY012 strain had a better degradation rates in the range ofpH 5.0 to 8.0, and the optimum $\mathrm{pH}$ was determined at 7.0(Figure 2B).

A

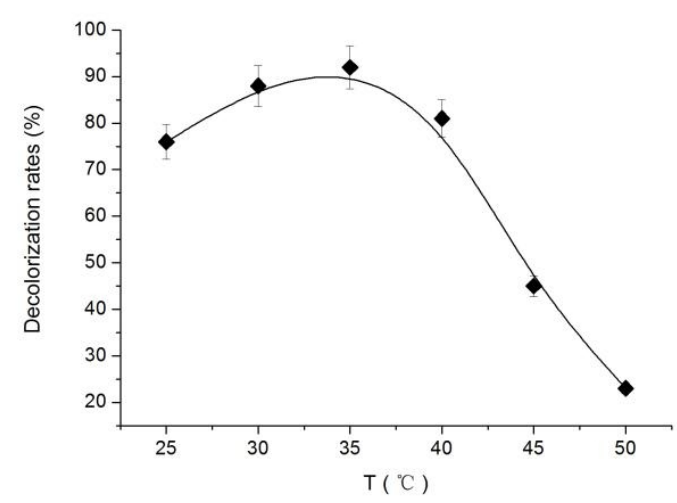

B

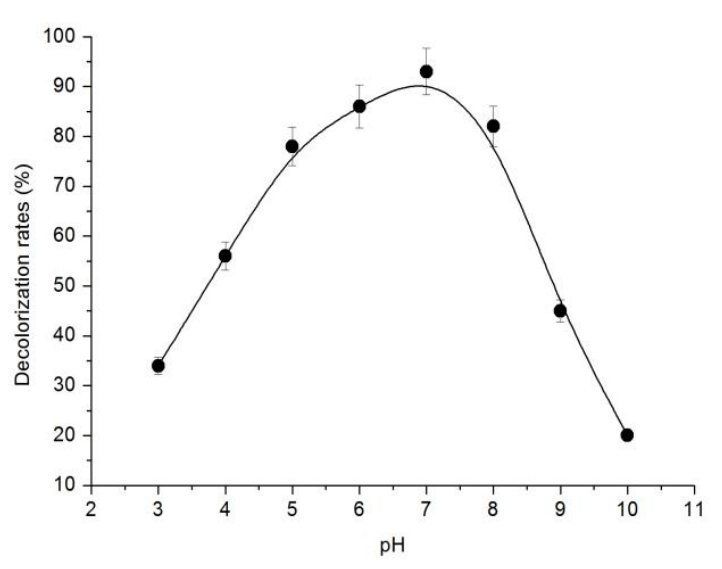

Figure 2. Results of optimization of decolorization condition. A: temperature; $\mathrm{B}$ : $\mathrm{pH}$

\section{Decolorization in different concentration of Direct blue 6}

To determine the effect of initial concentration on Direct Blue 6degradation, HS-DY012 strain was cultured in liquid MSM medium containing different concentration of Direct Blue 6, and adjusted $\mathrm{pH} 7.0,150 \mathrm{rpm}$ shaking at $35^{\circ} \mathrm{C}$. As showed from Figure 3, with the concentration increased, the dye biodegradationcapabilities of HS-DY012 was decreased. The degradation rate was less than 50\% when the concentration exceed $90 \mathrm{mg} / \mathrm{L}$, and the degradation rate was above $90 \%$ when the concentration was under $40 \mathrm{mg} / \mathrm{L}$. Whereas, the biomass was lower at $20 \mathrm{mg} / \mathrm{L}$ than that of 30 $\mathrm{mg} / \mathrm{L}$, meaning HS-DY012 strain could effectually degrade dye of Direct blue 6 at $20 \mathrm{mg} / \mathrm{L}$, but the sources of nutrition from degradation metabolins were not enough for bacteria growing. High 
concentration of Direct blue 6 was prevent decoloring and growing of bacteria , suggesting high concentration of dye was harmful to bacteria as a xenobiotic[10].

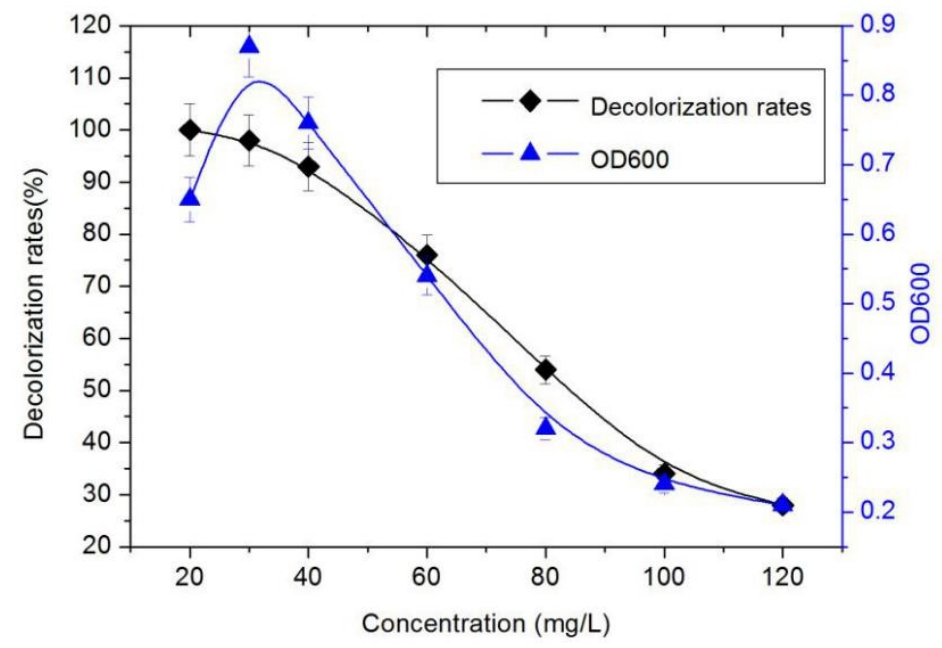

Figure 3. Decolorization and bacteria growth at different concentration

\section{Broad-spectrum dye degradation characteristics}

Broad-spectrum dye degradation was benefit to application in waste water treatment in painting and dyeing plant. Herein five different type dyes were selected as substrate of decolorization and degradation to measure broad-spectrum degradation characteristics of HS-DY012 (Table 1). They are belonged to Direct dye, Reactive dye, Acid dye and Vat dye respectively.

As showed in Figure 4, HS-DY012 strain could effectually decolor three dyes of the five, and the decolorization rates were over $90 \%$ respectively in the MSM medium at the concentration of 20 $\mathrm{mg} / \mathrm{L}$, two of them, i.e. Acid scarled GR and Vat Yellow 2, were decolorization at a lower lever.These results indicated that HS-DY012 strain have a high ability to decolor and degrade direct blue 6 with broad-spectrum dye decolorization and degradation characteristics.

Table 1 Molecular structure and properties of different types of dyes

\begin{tabular}{|c|c|c|c|}
\hline Dye & type & Structural formula & $/ \lambda \max (\mathbf{n m})$ \\
\hline Direct blue 6 & Direct dye & & 571 \\
\hline Reactive black 5 & Reactive dye & & 600 \\
\hline Acid scarled GR & Acid dye & & 510 \\
\hline Congo red & Direct dye & & 526 \\
\hline Vat yellow 2 & Vat dye & & 428 \\
\hline
\end{tabular}




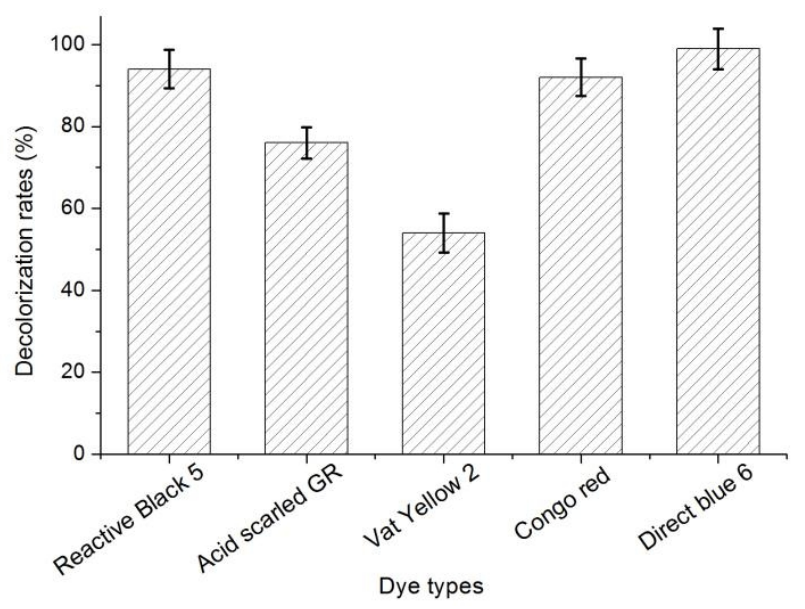

Figure 4. Decolorization rates of different dyes by HS-DY012 strain

\section{Conclusions}

HS-DY012 strain was original isolated from sludge samples in a dyeing plant and used to decolor and degrade Direct blue 6 dye. Dynamic analysis indicated that the Direct blue 6 dye with concentration of $30 \mathrm{mg} / \mathrm{L}$ was degraded completely by HS-DY012 strain within $12 \mathrm{~h}$ culturing at $35{ }^{\circ} \mathrm{C}$ on a shaker at $120 \mathrm{rpm}$. The optimum condition of decolorization and degradation were determined, i.e. temperature at $35^{\circ} \mathrm{C}$ and $\mathrm{pH} 7.0$, and the concentration was below $40 \mathrm{mg} / \mathrm{L}$ with a high gradation rate. HS-DY012 strain could effectually decolor three of the five dyes selected from four common types of dyestuffs, indicating HS-DY012 strain was a great degrader with a broad-spectrum dye decolorization and a high degradation rate.

\section{Acknowledgements}

This work was supported by the Foundation for InnovativeResearch Group of Hubei Educational Office(T201619); and the Key Grants of National Nature Science foundation of Hubei Province (2010CDA065) ; and the High Level Cultivation Project of HGNU (201615903).

\section{References}

[1] K. Kumar, D.S. Saravana,K. Krishnamurthi, S.Gampawar, N. Mishra, G. H. Pandya and T. Chakrabarti:Bioresource Vol .97(2006), p.407-413

[2] M. Wafaa A. El-Rahim, H. Moawad ,Z. Ahmed, AAbdel, J. Michael and Sadowsky: Journal of Biotechnology Vol.260(2017),p.11-17

[3] G.M.B.Soares, M.T.P. Amorim,R. Hrdina and M. Costa-Ferreira:Process Biochem Vol.37(2002), p.581-7

[4] J.Kunal, S.Varun , C.Digantkumar, M.Datta: In Journal of Hazardous Materials Vol.213214(2012), p.378-386

[5] R.C. Nagendranatha, K.A. Naresh and S. Venkata Mohan:In Journal of Hazardous Materials Vol.343(2018),p.49-58

[6] C.Liu, Y.You , R. Zhao, D.Sun ,P. Zhang, J. Jiang, A. Zhu and W. Liu: In Ecotoxicology and Environmental Safety Vol.145(2017), p. 8-15

[7] A. Naresh Kumar, C. Nagendranatha Reddy and S. Venkata Mohan: Bioresource Technology Vol.188 (2015),p. 56-64

[8] F. He,W. Hu and Y. Li :Chemosphere Vol.57(2004),p.293-301

[9] A. Kunamneni, I. Ghazi, S. Camarero, A. Ballesteros, F. J. Plou and M. Alcalde: Process Biochemistry Vol.43(2008), p.169-178

[10] S. Sen, S. Raut, P. Bandyopadhyay and S. Raut: Fungal Biology Reviews Vol.30(2016), p.112-133 